\title{
Redox sensor proteins for highly sensitive direct imaging of intracellular redox state
}

\section{Kazunori Sugiura $^{\mathrm{a}, \mathrm{b}, \mathrm{c}}$, Takeharu Nagai ${ }^{\mathrm{d}}$, Masahiro Nakanod, Hiroshi Ichinose ${ }^{\mathrm{b}}$, Takakazu}

Nakabayashi $^{\text {e,f }}$, Nobuhiro Ohta ${ }^{\mathrm{e}}$, Toru Hisaboria ${ }^{\mathrm{ab}, \mathrm{c},{ }^{*}}$

${ }^{a}$ Chemical Resources Laboratory, Tokyo Institute of Technology, Nagatsuta 4259-R1-8, Midori-

$\mathrm{Ku}$, Yokohama 226-8503, Japan

${ }^{\mathrm{b}}$ Graduate School of Bioscience and Biotechnology, Tokyo Institute of Technology, Nagatsuta 4259, Midori-Ku, Yokohama, 226-8501, Japan

${ }^{\mathrm{c} C o r e}$ Research for Evolutional Science and Technology (CREST), Japan Science and Technology Agency (JST), Tokyo 102-0075, Japan

${ }^{\mathrm{d}}$ The Institute of Scientific and Industrial Research, Osaka University, 8-1 Mihogaoka, Ibaraki, Osaka 567-0047, Japan

${ }^{\mathrm{e}}$ Research Institute for Electronic Science, Hokkaido University, Kita 20, Nishi 10, Kita-Ku, Sapporo 001-0020, Japan

${ }^{\mathrm{f}}$ Graduate School of Pharmaceutical Sciences, Tohoku University, Aoba-Ku, Sendai 980-8578, Japan.

*Correspondence should be addressed to Toru Hisabori;

Fax: 81-45-924-5268 Tel: 81-45-924-5234

E-mail address: thisabor@res.titech.ac.jp 


\begin{abstract}
Intracellular redox state is a critical factor for fundamental cellular functions, including regulation of the activities of various metabolic enzymes as well as ROS production and elimination. Genetically-encoded fluorescent redox sensors, such as roGFP (Hanson, G. T., et al. (2004)) and Redoxfluor (Yano, T., et al. (2010)), have been developed to investigate the redox state of living cells. However, these sensors are not useful in cells that contain, for example, other colored pigments. We therefore intended to obtain simpler redox sensor proteins, and have developed oxidation-sensitive fluorescent proteins called Oba-Q (oxidation balance sensed quenching) proteins. Our sensor proteins derived from CFP and Sirius can be used to monitor the intracellular redox state as their fluorescence is drastically quenched upon oxidation. These blue-shifted spectra of the Oba-Q proteins enable us to monitor various redox states in conjunction with other sensor proteins.
\end{abstract}

Keywords: biosensor, disulfide, fluorescence, oxidation-reduction, redox regulation.

\begin{abstract}
Abbreviations
roGFP, redox-sensitive GFP; YFP, yellow fluorescence protein; rxYFP, redox sensitive YFP; roGFPiX, roGFP with insertion $\mathrm{X}$ where $\mathrm{X}$ is the inserted amino acid; CFP, cyan fluorescence protein; FRET, Förster resonance energy transfer; BFP, blue fluorescence protein; AMS, 4acetoamido-4'-maleimidylistilbene-2, 2'-disulfonate; $\mathrm{GSSG}$, oxidized glutathione; $\mathrm{OxD}_{\mathrm{GSH}}$, the ratio of GSSG to the total glutathione.
\end{abstract}




\section{Introduction}

Changes in cellular redox balance must easily affect cell viability due to fluctuation of a variety of enzymatic activities and macromolecular conditions. For example, changes in the thioldisulfide equilibrium within proteins directly affect their enzymatic activities and protein-protein interactions via conformational changes. These changes may induce a variety of phenomena, including proliferation, differentiation, and programed cell death [1]. Cellular redox homeostasis should be therefore strictly maintained. To evaluate redox status in vivo, a variety of redox sensors have been developed. roGFP is the most popular sensor protein, which was produced by the introduction of two cysteine residues on the surface of GFP that can form a disulfide-bond [2]. Introduction of two cysteines at positions Ser147 and Gln204 of wild-type GFP or GFP-S65T, produced redox sensors designated roGFP1 and roGFP2, respectively. These roGFPs show two excitation peaks at approximately 400 and $490 \mathrm{~nm}$. The ratio of the fluorescence intensities of these peaks changes with the formation and dissociation of the disulfide-bond, and the in vivo redox potential can be monitored by measuring excitation spectra. Similar sensor protein rxYFP had been designed before roGFP [3]. rxYFP has a single excitation peak at around $512 \mathrm{~nm}$, and the fluorescence intensity is affected by redox change. The midpoint redox potentials of roGFP1, roGFP2, and rxYFP have been reported to be $-287 \mathrm{mV},-272 \mathrm{mV}$, and $-261 \mathrm{mV}$, respectively $[2,3]$. These values are suitable for use in a reducing environment, such as the mitochondrial matrix $(-360 \mathrm{mV})$ [2] and the cytoplasm $(-320 \mathrm{mV})$ [4] of HeLa cells. In contrast, Lohman and Remington created roGFP1 mutants with higher midpoint redox potentials by inserting a single amino acid at the position to the C-terminal side of Cys147 and the substitution of His148 with Ser [5]. The mutants obtained were named roGFPiX, where $\mathrm{X}$ is the single character code of the inserted amino acid. They have higher midpoint potentials, approximately $-229 \mathrm{mV}$ to $-246 \mathrm{mV}$, and are suitable for monitoring a redox environment under oxidative conditions, such as in the endoplasmic reticulum (ER) $(-210 \mathrm{mV})$ [5]. The fluorescence lifetime of roGFPiX is changed drastically by oxidation and reduction [6].

roGFP is, however, not easily reduced or oxidized by glutathione or $\mathrm{H}_{2} \mathrm{O}_{2}$. To overcome this disadvantage, Gutscher et al. demonstrated that the fusion of human Grx1 to roGFP2 facilitates a redox equilibrium between glutathione and the thiol moiety of roGFP [7]. In addition, they reported that Orp1 mediates the interaction between $\mathrm{H}_{2} \mathrm{O}_{2}$ and roGFP2 when fused to roGFP2 [8].

As mentioned, all the foregoing redox sensors were prepared on the basis of GFP or YFP, which have Tyr66 in their chromophores. Their redox responses are, therefore, based on a change in the ionization equilibrium of Tyr66. However, the appropriate image analysis system should be required to use them simultaneously, because emission peaks are overlapped.

A new type of redox sensor, Redoxfluor, was recently developed [9]. The efficiency of 
FRET between the chromophores of CFP and YFP in this protein is used as an indicator [9]. However, the emission wavelength of Redoxfluor also overlaps with that of other GFP-based sensor proteins.

Many variants of GFP with different fluorescence colors, such as CFP, BFP, and YFP, have been prepared by the mutagenesis of the chromophore sequence and the surrounding barrel structure $[10,11,12]$. In order to develop a new redox indicator protein, we chose Sirius, which shows the emission peak at $424 \mathrm{~nm}$ [13], and mTurquoise, a variant of CFP [14], and successfully obtained useful redox sensors. In contrast to the conventional GFP-based redox sensors reported so far, our proteins show a reversible decrease in quantum yield only by oxidation. Therefore, we named them oxidation balance sensed quenching proteins, Oba-Q. Oba-Q Sirius (Oba-Qs) and Oba-Q CFP (Oba-Qc) are powerful tools because they enable us to monitor various in vivo redox states together with other GFP-based sensors. In addition, we also created a human glutaredoxin1 fusion with Oba-Q CFP (Grx1-Oba-Qc) as reported [7]. Grx1-Oba-Qc shows a drastic change in fluorescence caused by changes in redox balance of glutathione.

\section{Materials and Methods}

\subsection{Gene Construction, Mutagenesis, and Protein Expression/Purification}

To obtain Oba-Qs and Oba-Qc, the genes for Sirius and CFP' in pET23a were used as templates, and all point mutations and initial insertions were introduced using the PrimeSTAR ${ }^{\circledR}$ Mutagenesis Basal Kit (TAKARA, Tokyo). To confer CFP property, several mutations were introduced into the gene for Sirius (designated CFP'). Mutations introduced into Sirius and CFP' are shown in Supplemental Figs. 1 and 2, respectively. Mutant proteins were expressed in E. coli strain BL21. Cultures were allowed to reach an $\mathrm{OD}_{600}$ between 0.4 and 0.8 at $37^{\circ} \mathrm{C}$, and then the temperature was reduced to $25^{\circ} \mathrm{C}$ overnight in the presence of a $1 \mathrm{mM}$ isopropyl $\beta$-D-1thiogalactopyranoside. Cells were then harvested by centrifugation, re-suspended in $20 \mathrm{mM}$ Tris$\mathrm{HCl}\left(\mathrm{pH}\right.$ 8.0) and disrupted using French pressure cells. Cell lysates were boiled at $70^{\circ} \mathrm{C}$ for 10 min, and centrifuged to remove the denatured proteins. The supernatants were then applied to a TOYOPEARL Butyl-650 (TOSOH, Tokyo) column and eluted using $20 \mathrm{mM}$ Tris- $\mathrm{HCl}$ (pH 8.0) with an ammonium sulfate reverse-gradient from $20 \%$ to $0 \%$. Peak fractions eluted from the column were collected, dialyzed, and concentrated.

For Grx1-ObaQc, an expression vector was generated to fuse human Grx1 with Oba-Qc using the linker (GGSGG)6. A His $\sigma_{-}$-tag was added at the C-terminus of Oba-Qc. E. coli strain and cultivation conditions were the same as those for Oba-Q proteins. The cell lysate was centrifuged and the supernatant was applied to a Ni-NTA Superflow column (Qiagen). The desired protein was eluted using $100 \mathrm{mM}$ imidazole. The peak fraction was collected and applied to a 
TOYOPEARL Butyl-650 (TOSOH) column, eluted, and concentrated as described.

To obtain Oba-Qb, the gene of EBFP2-His 6 in pet23a was used, and all mutations were introduced as indicated (Supplemental Fig. 3). The desired protein was obtained by the same procedures as described.

\subsection{Fluorescence spectroscopy}

Fluorescence excitation/emission spectra were measured using a FP-8500 fluorescence spectrophotometer (JASCO, Tokyo). For Sirius-based mutants, excitation wavelength of $370 \mathrm{~nm}$ and emission wavelength of $425 \mathrm{~nm}$ were used. $430 \mathrm{~nm}$ and $480 \mathrm{~nm}$ for CFP variants, and 380 $\mathrm{nm}$ and $440 \mathrm{~nm}$ for Oba-Qb were used, respectively.

\subsection{In vitro measurements of oxidation and reduction of Oba-Q proteins}

Oba-Qs and Oba-Qc were incubated with final concentrations of $50 \mu \mathrm{M} \mathrm{CuCl}_{2}$ or 1-5 $\mathrm{mM}$ DTT for $10 \mathrm{~min}$. EDTA was then added to be $2 \mathrm{mM}$. The redox states of the Oba-Q proteins were determined by SDS-PAGE as follows. Oxidized and reduced proteins were then labeled with 4-acetoamido-4'-maleimidylistilbene-2,2'-disulfonate (AMS) (Invitorogen) as described [15]. Proteins were separated on $12 \%$ SDS-PAGE.

\subsection{Measurement of quantum yield}

The quantum yield was measured using a Quantaurus-QY (Hamamatsu Photonics, Hamamatsu). Oxidized and reduced forms of Oba-Q proteins were prepared, and a light beam at $355 \mathrm{~nm}$ (for Oba-Qs) and $430 \mathrm{~nm}$ (for Oba-Qc) were used for excitation.

\subsection{Measurement of fluorescence lifetime}

Fluorescence decay profiles were measured by a time-correlated single photon counting method [16]. The second harmonic of the output from a femtosecond mode-locked Ti:sapphire laser (Spectra Physics, Santa Clara), the repetition rate of which was reduced to approximately 6 $\mathrm{MHz}$, was used for excitation. Fluorescence dispersed by a monochromator was detected using a microchannel-plate photomultiplier (Hamamatsu Photonics, Hamamatsu). The instrumental response function had a full width at half maximum of approximately $60 \mathrm{ps}$. All the decay profiles were measured at a magic angle condition with respect to the vertically polarized excitation light. Excitation and detection wavelengths were 383 and $440 \mathrm{~nm}$ for Oba-Qs and 420 and $500 \mathrm{~nm}$ for Oba-Qc, respectively.

\subsection{Calculation of Midpoint Redox Potentials}

The apparent midpoint redox potentials of the Oba-Q proteins were determined on the basis of 
the method described by Hanson et al [2]. To determine the molecular ratio between the oxidized and reduced forms, the protein samples to be equilibrated were prepared at $1 \mu \mathrm{M}$ in $50 \mathrm{mM}$ MOPS ( $\mathrm{pH}$ 7.0) containing $20 \mathrm{mM}$ DTT (a mixture of oxidized and reduced forms), and incubated for 3 h. The fluorescence spectra were then measured at $25^{\circ} \mathrm{C}$. Based on the calculated concentrations of $\mathrm{DTT}_{\text {red }}$ and $\mathrm{DTT}_{\text {ox }}$ at equilibrium, the redox potential of the protein was calculated by applying the Nernst equation:

$E=E^{\prime}{ }_{0(D T T)}+(R T / n F) \times \ln \left[D T T_{o x}\right] /\left[D T T_{\text {red }}\right] \quad($ Eq. 1)

where $E_{0 \text { (DTT) }}^{\prime}$ is the biochemist's standard potential of the $\mathrm{DTT}_{\text {red }} / \mathrm{DTT}_{\text {ox }}$ couple $(-0.33 \mathrm{~V}$, at $\mathrm{pH}$ 7 and $25^{\circ} \mathrm{C}$ ), $R$ is the gas constant, $T$ is the absolute temperature, $n$ is the number of transferred electrons (2), and $F$ is the Faraday constant. To determine the fraction of the reduced form of ObaQ proteins, the fluorescence intensities of these proteins were denoted by $\Phi$ and used for analysis. $\Phi_{\mathrm{red}}$ and $\Phi_{\mathrm{ox}}$ represent the fluorescence intensities of the fully reduced and fully oxidized forms, respectively. $R$ ' was determined using Equation 2. Concentrations of oxidized and reduced Oba$\mathrm{Q}$ in solution ([Oba- $\left.\mathrm{Q}_{\mathrm{ox}}\right]$ and $\left.\left[\mathrm{Oba}-\mathrm{Q}_{\mathrm{red}}\right]\right)$ were then calculated using Equations 3 and 4.

$R^{\prime}=\left(\Phi-\Phi_{\mathrm{ox}} /\left(\Phi_{\mathrm{red}}-\Phi_{\mathrm{ox}}\right)\right.$
$\left[\mathrm{Oba}-Q_{\text {red }}\right]=R^{\prime}\left[\mathrm{Oba}-Q_{o x-i}\right]$
$\left[\right.$ Oba- $\left.Q_{o x}\right]=\left(1-R^{\prime}\right)\left[\mathrm{Oba}-Q_{o x-i}\right]$

The midpoint potentials of the Oba-Q proteins [E' $\left.{ }_{0(\mathrm{Oba}-\mathrm{Q})}\right]$ were calculated using Equation 5:

$E^{\prime}{ }_{0(\mathrm{Oba}-\mathrm{Q})}=E^{\prime}{ }_{0(\mathrm{D} T T)}+(\mathrm{RT} / \mathrm{nF}) \times \ln \alpha\left[\mathrm{Oba}-Q_{o x}\right] /\left[\mathrm{Oba}-Q_{\text {red }}\right]$

where $\alpha$ is the ratio of the activity coefficients of oxidized and reduced Oba-Q. We plotted E for $\mathrm{x}$-axis and $\mathrm{R}^{\prime}$ for $\mathrm{y}$-axis, and fitted the curve with Equation 6:

$y=1 /\left[1+\exp \left\{\left(x-A_{1}\right) A_{2}\right\}\right] \quad$ (Eq. 6)

where $A_{1}$ and $A_{2}$ are fitting coefficients, and $A_{1}$ gives the midpoint redox potential of the protein of interest.

\subsection{Imaging redox status in HeLa cells}

Oba-Q proteins were expressed in HeLaS3 cells using a modified pEGFP-N1 expression vector (Addgene), and Lipofectamin2000 (Lifetechnologies) as the transfection reagent. After 
incubation for $24 \mathrm{~h}$ at $37^{\circ} \mathrm{C}$, the transfected cells were washed with observation medium without phenol-red. Cells were then imaged on a multiple-point scanning confocal microscopy system comprising a microscope, a Ti-E (Nikon) with EMCCD camera iXon3 (ANDOR); a Nipkow disk CSU (CSU-X1, Yokogawa Electric, Tokyo Japan) equipped with a Light Engine (Lumencor); and an electro-motion XY stage, BIXY stage STD system (Chuo Precision Industrial Co., LTD.). These equipments were controlled by MetaMorph software (Molecular Devices). The fluorescence image was monitored using excitation filter FF01-386/23-25, emission filter FF02438/24-25, and dichroic mirror OPTO-Di-BGR-LLSY (Opto-Line) for the Oba-Qs mutants; and excitation filter FF02-438/24-25, emission filter FF01-483/32-25, and dichroic mirror Di01T442/505/635-13x15x0.5 (Semrock) for Oba-Qc mutants. The intensity of the fluorescence image was then digitalized by ImageJ software.

\section{Results and Discussion}

\subsection{Basic design of new redox sensitive proteins}

New redox sensing proteins were designed based on the molecular design of roGFP [2]. In both roGFP1 and roGFP2, Ser147 and Gln204 were chosen as positions for cysteine substitution, and a redox change in the micro-environment around the chromophore was detected as a change in the fluorescence spectrum [2]. We first introduced several mutations into the gene encoding Sirius to make it similar to mTurquoise and designated it CFP'. Although CFP' has a different primary sequence from the original ECFP (enhanced CFP), it maintains the spectroscopic properties of ECFP and mTurquoise. We then introduced cysteines into Sirius and CFP' at the same positions as roGFP1. However, neither of the mutants, Sirius $\mathrm{S}_{147 \mathrm{C} / \mathrm{Q} 204 \mathrm{C}}$ (Sirius2C) and CFP's147C/Q204C (CFP2C), showed any change in fluorescence or excitation spectra, nor did their fluorescence intensities change under oxidizing and reducing conditions (Supplemental Fig. 4A for Sirius, and 4B for CFP'). We then inserted one amino acid into the Cterminal side of Cys147 in Sirius2C (Sirius2 $\mathrm{C}_{\mathrm{S147CX}}$ ) and CFP2C (CFP2C $\mathrm{C}_{\mathrm{S} 147 \mathrm{CX}}$ ). A remarkable change was observed in the fluorescence intensity of Sirius $2 \mathrm{C}_{\mathrm{S} 147 \mathrm{CD}}$ due to the formation and reduction of its disulfide-bond (Supplemental Fig. 4A). However, $\mathrm{CFP} 2 \mathrm{C}_{\mathrm{S} 147 \mathrm{CX}}$ variants did not show any redox changes in fluorescence (Supplemental Fig. 4B). We therefore introduced an additional point mutation at Ile146 of CFP, which is critical to determine the quantum yield of fluorescence [17]. In addition, we expected that the conformation around Ile146 would be substantially affected by a disulfide-bond formation as reported for roGFP1iE [5]. When Ile146 of Sirius $2 \mathrm{C}_{\mathrm{S} 147 \mathrm{CD}}$ was mutated to Asn, a remarkable quench was observed upon oxidation. Point mutation at Ile146 of CFP also affected the quench rate, and the largest change was observed when Ile146 of CFP2 $\mathrm{C}_{\mathrm{S} 147 \mathrm{CE}}$ was substituted with Gly. We designated them oxidation balance 
sensed quenching proteins (Oba-Q) based on their interesting fluorescence properties. Hereafter, we will refer to Sirius2 $\mathrm{C}_{1146 \mathrm{~N} / \mathrm{S} 147 \mathrm{CD}}$ as Oba-Qs (Supplemental Fig. 4A), and CFP2 $\mathrm{C}_{\mathrm{I1} 146 \mathrm{G} / \mathrm{S} 147 \mathrm{CE}}$ as Oba-Qc (Supplemental Fig. 4B).

\subsection{Characterization of Oba- $Q$ proteins}

Complete oxidation and reduction of proteins were confirmed by non-reducing SDSPAGE followed by AMS labeling [18] (Fig. 1A). Although the original Sirius and CFP', which do not contain cysteines, and Sirius2C and CFP2C, which contain two cysteines, did not show any significant redox responses, Oba-Q proteins showed a drastic quench by oxidation as mentioned. Their excitation and emission peaks are same as those of the original Sirius and CFP', but their fluorescence intensities are simply dependent on their redox status (Figs. 1B and 1C). In contrast, they did not show any redox response in their absorbance spectra (Figs. 1D and 1E). The quantum yields of the reduced forms were approximately 6.3-fold higher for Oba-Qs and 2.3-fold for Oba-Qc, respectively, than those of the oxidized forms (Table 1). The fluorescence life-times showed substantial changes according to their redox states as well (Figs. 1F and 1G, and Table 1).

We determined the redox midpoint potentials using a plot of the fraction of reduced protein versus the ratio of $\mathrm{DTT}_{\text {red/ox }}$, as described [2]. Consequently, values of $-232 \mathrm{mV}$ and -249 $\mathrm{mV}$ were obtained for Oba-Qs and Oba-Qc, respectively (Figs. 2A and 2B). The redox potential of Oba-Qs was too high to use it in the cytoplasm $(-320 \mathrm{mV})$ [4] or mitochondria $(-360 \mathrm{mV})$ [2] of HeLa cells. However, it is suitable for use in ER $(-230 \mathrm{mV})$ [19]. The roGFP variant that has a midpoint potential closest to Oba-Qs has been used to monitor ER redox homeostasis in human cells [6]. The redox potential of Oba-Qc $(-249 \mathrm{mV})$ is close to that of rxYFP, which was used for monitoring the cytosolic thiol/disulfide equilibrium of Saccharomyces cerevisiae and Escherichia coli $[3,20]$. During the process of attenuating the Oba-Q proteins, we realized that the midpoint redox potentials of the Oba-Q proteins are easily influenced by the identity of the inserted amino acid residue. For example, Oba-Qss147cG showed lower midpoint potential, $-251 \mathrm{mV}$ (Fig. 2A), whereas almost the same spectroscopic properties as Oba-Qs. This implies that we can easily create further variants that can be used at lower midpoint potentials.

The fluorescence intensities of both the reduced and oxidized forms of Oba-Qs are dependent on $\mathrm{pH}$ (Fig. 2C). In contrast, the observed fluorescence intensities of Oba-Qc are mostly stable between pH 6.0 and 8.0 (Fig. 2D).

\subsection{Construction of $\mathrm{Oba}-\mathrm{Qb}$}

By the introduction of mutations as described, we successfully prepared the redox sensitive BFP, BFP2C $\mathrm{C}_{\mathrm{S} 147 \mathrm{CX}}$, and designated Oba-Qb. By the oxidation (Supplemental Fig. 5A), excitation and emission peaks are immediately decreased though the absorption spectra were 
somehow affected (Supplemental Figs. 5B and 5C). The redox potential -263 mV (Supplemental Fig. 5D) is suitable for monitoring the cytosolic thiol/disulfide equilibrium. Hence, our design is certainly applicable to the multiple GFP variants to produce redox sensitive proteins.

\subsection{Equilibrium between glutathione and Oba-Qc catalyzed by Grx 1}

Changes in the redox state within the cell are mainly caused by changes in the balance between the reduced and oxidized forms of glutathione. Therefore, it would be informative if the redox sensor protein responds to the redox balance of glutathione. Although the original roGFP did not show any sensitivity to glutathione [2], a human glutaredoxin-1 (Grx1)-roGFP2 fusion protein could monitor the glutathione redox balance in vivo [7]. We simply applied this strategy to our Oba-Q proteins, and prepared Grx1-Oba-Qc. A 30-amino-acid linker (Gly-Gly-Ser-GlyGly)6 was used to connect them as described [7]. Grx1-Oba-Qc showed remarkable changes in fluorescence intensity in vitro dependent on the concentration of oxidized glutathione. The fluorescence intensit of the reduced form Grx1-Oba-Qc was remarkably decreased when $10 \mu \mathrm{M}$ GSSG was added, indicating Grx1 can efficiently oxidize Oba-Qc part (Fig. 3). In contrast, the Oba-Qc itself was not oxidized even in the presence of $200 \mu \mathrm{M}$ GSSG. The useful reaction range of Grx1-Oba-Qc was between $\mathrm{OxD}_{\mathrm{GSH}}$ values of about 0.05 and 0.5 (Fig. 3C). $\mathrm{OxD}_{\mathrm{GSH}}$ is the ratio of the concentration of the oxidized form, GSSG, to the total glutathione concentration;

$O x D_{G S H}=2[G S S G] /(2[G S S G]+[G S H]) \quad($ Eq. 7$)$

However, Grx1-Oba-Qc was not completely oxidized even in the presence of $500 \mu \mathrm{M}$ GSSG and $1 \mathrm{mM} \mathrm{GSH} \mathrm{(Fig.} \mathrm{3C,} \mathrm{closed} \mathrm{square} \mathrm{for} \mathrm{OxD}_{\mathrm{GSH}}=0.5$ ), although Grx1-roGFP2 was fully oxidized [7]. This discrepancy may be explained by the difference of the midpoint potentials, $-249 \mathrm{mV}$ for Oba-Qc and $-272 \mathrm{mV}$ for roGFP2 [2]. The response range of Grx1-roGFP2 was from 0.0015 to $0.002 \mathrm{OxD}_{\mathrm{GSH}}$. Because $\mathrm{OxD}_{\mathrm{GSH}}$ values of 0.02 to 0.06 [21] in mammalian cells is reported, Grx1-Oba-Qc must be less suitable than Grx1-roGFP2 to monitor reduced environments. Grx1-Oba-Qc and Grx1 fusion Oba-Q variants with lower redox potentials must be useful in more oxidized environments, such as that found in $\mathrm{ER}\left(\mathrm{OxD}_{\mathrm{GSH}}=0.25\right.$ to 0.67$)$.

\subsection{Response of Oba- $Q$ proteins in living cells}

We then expressed Oba-Q proteins in HeLaS3 cells. They were reduced forms in cells under standard culture conditions. These results were expected, given that intracellular glutathione redox balance is too reductive to oxidize Oba-Q proteins. However, when cells were exposed to $1 \mathrm{mM}$ diamide, a rapid quench of the fluorescence was observed (Fig. 4). This quench was easily recovered when $1 \mathrm{mM}$ DTT was added. In contrast, the response to $\mathrm{H}_{2} \mathrm{O}_{2}$ was very different. 
When cells possessing Oba-Qc was exposed to $1 \mathrm{mM} \mathrm{H}_{2} \mathrm{O}_{2}$, a rapid but slight quench (only $10 \%$ ) was observed and was easily recovered with $1 \mathrm{mM}$ DTT. In the case of Oba-Qs, a remarkable quench was not observed under conditions similar to those used for Oba-Qc, indicating that ObaQs is not sufficiently oxidized by $\mathrm{H}_{2} \mathrm{O}_{2}$. In contrast, Grx1-Oba-Qc responded more rapidly to $\mathrm{H}_{2} \mathrm{O}_{2}$, and its fluorescence was recovered by $1 \mathrm{mM}$ DTT. These results imply that $\mathrm{H}_{2} \mathrm{O}_{2}$ does not oxidize these proteins directly. Rather, it changes the redox balance, which will ultimately affect the redox balance of glutathione. In contrast, diamide may oxidize Oba-Q proteins directly, because the time courses of the changes in Oba-Qs and Oba-Qc fluorescence after the addition of diamide were very similar.

\subsection{Advantage and disadvantage of Oba- $Q$ proteins}

We developed three redox sensitive fluorescence proteins named Oba-Qb, Oba-Qc and Oba-Qs. The most interesting property of these proteins is the remarkable decrease in quantum yield that occurs upon oxidation. Although they do not permit ratiometric measurement since their signals must be easily influenced by their expression level, the observed quenching make it easy to apply them for the observation under the conventional fluorescence microscope. These proteins have different chromophores, but mutations at the same positions confer very similar redox sensitivity. This implies that we will be able to create another sensor proteins with different colors by introducing the same mutations into other GFP variants and to create a multicolor redox imaging system, which can show the different redox situations of the various intracellular organella.

\section{AKNOWLEDGEMENTS}

This work was supported in part by a Postdoctoral Fellowship (to K. S.) from JSPS, and CREST from JST (to T. H.), and was supported in part by the Nano-Macro Materials, Devices and System Research Alliance, MEXT, Japan. We thank A. Isu and Y. Aizawa for technical assistance.

\section{References}

[1] F.Q. Schafer, G.R. Buettner, Redox environment of the cell as viewed through the redox state of the glutathione disulfide/glutathione couple, Free Radic Biol Med 30 (2001) 1191-1212.

[2] G.T. Hanson, R. Aggeler, D. Oglesbee, M. Cannon, R.A. Capaldi, R.Y. Tsien, S.J. Remington, Investigating mitochondrial redox potential with redox-sensitive green fluorescent protein indicators, J Biol Chem 279 (2004) 13044-13053.

[3] H. Ostergaard, A. Henriksen, F.G. Hansen, J.R. Winther, Shedding light on disulfide bond 
formation: engineering a redox switch in green fluorescent protein, EMBO J 20 (2001) 5853-5862.

[4] C.T. Dooley, T.M. Dore, G.T. Hanson, W.C. Jackson, S.J. Remington, R.Y. Tsien, Imaging dynamic redox changes in mammalian cells with green fluorescent protein indicators, $\mathrm{J}$ Biol Chem 279 (2004) 22284-22293.

[5] J.R. Lohman, S.J. Remington, Development of a family of redox-sensitive green fluorescent protein indicators for use in relatively oxidizing subcellular environments, Biochemistry 47 (2008) 8678-8688.

[6] E. Avezov, B.C. Cross, G.S. Kaminski Schierle, M. Winters, H.P. Harding, E.P. Melo, C.F. Kaminski, D. Ron, Lifetime imaging of a fluorescent protein sensor reveals surprising stability of ER thiol redox, J Cell Biol 201 (2013) 337-349.

[7] M. Gutscher, A.L. Pauleau, L. Marty, T. Brach, G.H. Wabnitz, Y. Samstag, A.J. Meyer, T.P. Dick, Real-time imaging of the intracellular glutathione redox potential, Nat Methods 5 (2008) 553-559.

[8] M. Gutscher, M.C. Sobotta, G.H. Wabnitz, S. Ballikaya, A.J. Meyer, Y. Samstag, T.P. Dick, Proximity-based protein thiol oxidation by $\mathrm{H} 2 \mathrm{O} 2$-scavenging peroxidases, J Biol Chem 284 (2009) 31532-31540.

[9] T. Yano, M. Oku, N. Akeyama, A. Itoyama, H. Yurimoto, S. Kuge, Y. Fujiki, Y. Sakai, A novel fluorescent sensor protein for visualization of redox states in the cytoplasm and in peroxisomes, Mol Cell Biol 30 (2010) 3758-3766.

[10] R.Y. Tsien, The green fluorescent protein, Annu Rev Biochem 67 (1998) 509-544.

[11] G.J. Palm, A. Wlodawer, Spectral variants of green fluorescent protein, Methods Enzymol 302 (1999) 378-394.

[12] S.J. Remington, Structural basis for understanding spectral variations in green fluorescent protein, Methods Enzymol 305 (2000) 196-211.

[13] W. Tomosugi, T. Matsuda, T. Tani, T. Nemoto, I. Kotera, K. Saito, K. Horikawa, T. Nagai, An ultramarine fluorescent protein with increased photostability and $\mathrm{pH}$ insensitivity, Nat Methods 6 (2009) 351-353.

[14] K.A. Walther, B. Papke, M.B. Sinn, K. Michel, A. Kinkhabwala, Precise measurement of protein interacting fractions with fluorescence lifetime imaging microscopy, Mol Biosyst 7 (2011) 322-336.

[15] K. Motohashi, A. Kondoh, M.T. Stumpp, T. Hisabori, Comprehensive survey of proteins targeted by chloroplast thioredoxin, Proc Natl Acad Sci U S A 98 (2001) 11224-11229.

[16] M. Tsushima, T. Ushizaka, N. Ohta, Time-resolved measurement system of electrofluorescence spectra, Review of Scientific Instruments 75 (2004) 479-485.

[17] J. Goedhart, D. von Stetten, M. Noirclerc-Savoye, M. Lelimousin, L. Joosen, M.A. Hink, 
L. van Weeren, T.W. Gadella, Jr., A. Royant, Structure-guided evolution of cyan fluorescent proteins towards a quantum yield of 93\%, Nat Commun 3 (2012) 751.

[18] T. Kobayashi, S. Kishigami, M. Sone, H. Inokuchi, T. Mogi, K. Ito, Respiratory chain is required to maintain oxidized states of the DsbA-DsbB disulfide bond formation system in aerobically growing Escherichia coli cells, Proc Natl Acad Sci U S A 94 (1997) 11857-11862.

[19] M. van Lith, S. Tiwari, J. Pediani, G. Milligan, N.J. Bulleid, Real-time monitoring of redox changes in the mammalian endoplasmic reticulum, J Cell Sci 124 (2011) 2349-2356.

[20] H. Ostergaard, C. Tachibana, J.R. Winther, Monitoring disulfide bond formation in the eukaryotic cytosol, J Cell Biol 166 (2004) 337-345.

[21] C. Hwang, A.J. Sinskey, H.F. Lodish, Oxidized redox state of glutathione in the endoplasmic reticulum, Science 257 (1992) 1496-1502. 


\section{Figure legends}

Fig. 1. Spectrophotometric properties of Oba-Q proteins. (A) Full oxidation and reduction of ObaQ proteins were confirmed by non-reducing SDS-PAGE followed by AMS-labeling. For oxidation, the protein sample was treated with $50 \mu \mathrm{M} \mathrm{CuCl}_{2}$ for $10 \mathrm{~min}$, and for reduction incubated with $1 \mathrm{mM}$ DTT for $10 \mathrm{~min}$. $(B, C)$ Excitation (dotted lines, $\mathrm{R}_{\mathrm{x}}$ and $\mathrm{O}_{\mathrm{x}}$ ) and emission (solid lines, $\mathrm{R}_{\mathrm{m}}$ and $\mathrm{O}_{\mathrm{m}}$ ) spectra of the oxidized (black lines, $\mathrm{O}_{\mathrm{x}}$ and $\mathrm{O}_{\mathrm{m}}$ ) and reduced (red lines, $\mathrm{R}_{\mathrm{x}}$ and $\mathrm{R}_{\mathrm{m}}$ ) forms of Oba-Qs $(B)$ and Oba-Qc $(C)$. ( $\left.D, E\right)$ Absorption spectra of the oxidized (black lines) and reduced (red lines) forms of Oba-Qs $(D)$ and Oba-Qc $(E) .(F, G)$ Fluorescence decay curves of the oxidized (black lines) and reduced (red lines) forms of Oba-Qs $(F)$, and Oba-Qc $(G)$.

Fig. 2. Redox potential and $\mathrm{pH}$ dependency of Oba-Qs and Oba-Qc. (A) Redox potential of ObaQs (closed circle) and Oba-Qss147CG (closed square) were determined at $\mathrm{pH} 7.0$ by plotting the fraction of reduced protein, which was estimated from the fluorescence intensities, versus the ratio of $\mathrm{DTT}_{\text {red }}$ to $\mathrm{DTT}_{\text {ox }}$ and fitting the data on a titration curve. $(B)$ Redox potential of Oba-Qc (open circle) was determined at $\mathrm{pH} 7.0$ by plotting the fraction of reduced protein as for $A$. $(C, D)$ Fluorescence from recombinant Oba-Qs $(C)$ and Oba-Qc $(D)$ in different $\mathrm{pH}$ were measured for their oxidized (closed triangle) and reduced (closed square) forms, and their ratio was calculated (open circle). Buffers MES (for $\mathrm{pH}$ 6.0-6.4), PIPES (for $\mathrm{pH}$ 6.4-7.2), and HEPES (for $\mathrm{pH} 7.2-$ 8.0) were used.

Fig. 3. Oxidation of Grx1-Oba-Q fusion proteins in the presence of oxidized glutathione. $(A, B)$ Oba-Qc $(A)$ and Grx1-Oba-Qc $(B)$ were diluted to a final concentration of $100 \mathrm{nM}$ and oxidized glutathione was added (filled arrow) to a final concentration of $200 \mu \mathrm{M}$ for $A$, and $10 \mu \mathrm{M}$ and 200 $\mu \mathrm{M}$ for $B$. (C) $100 \mathrm{nM}$ Grx1-Oba-Qc was incubated in $20 \mathrm{mM}$ Tris- $\mathrm{HCl}(\mathrm{pH} 8.0)$, and $2 \mathrm{mM}$ GSSG was added (filled arrow) to create OxDGSH values of 0 (closed circle), 0.05 (open diamond), 0.1 (closed diamond), 0.2 (open square), and 0.5 (closed square).

Fig. 4. Fluorescence redox responses of Oba-Q proteins in living cellst. HeLaS3 cells expressing Oba-Q proteins were observed under a confocal fluorescence microscope. $(A)$ The images of the cells before the addition of diamide or $\mathrm{H}_{2} \mathrm{O}_{2}$ were shown as time $0(0 \mathrm{~min})$. One $\mathrm{mM}$ diamide or $\mathrm{H}_{2} \mathrm{O}_{2}$ were added at $5 \mathrm{~min}, 3 \mathrm{mM}$ DTT was added at $20 \mathrm{~min}$. Fluorescence images of the cells at the indicated time were presented. Distilled water was used as a control. Scale bar, $20 \mu \mathrm{m}$. $(B)$ Relative intensities of emission from 15 cell images for Oba-Qs and Oba-Qc and 10 cell images for Grx1-Qba-Qc were averaged at the indicated time. Arrows indicate the times at which $1 \mathrm{mM}$ diamide or $\mathrm{H}_{2} \mathrm{O}_{2}$ (filled arrow) and $3 \mathrm{mM}$ DTT (open arrow) were added. 
Table 1. Comparison of spectroscopic properties of Oba-Q proteins with Sirius and CFP.

\begin{tabular}{|c|c|c|c|c|c|c|}
\hline \multirow{2}{*}{ protein } & \multirow{2}{*}{$\varepsilon\left(10^{3} \mathrm{M}^{-1} \mathrm{~cm}^{-1}\right)$} & \multicolumn{2}{|c|}{ Quantum yield } & \multicolumn{2}{|c|}{ Lifetime (ns) } & \multirow{2}{*}{$\begin{array}{c}\mathrm{E}_{0} \\
(\mathrm{mV})\end{array}$} \\
\hline & & red & ox & red & ox & \\
\hline Sirius & 15 & 0.23 & 0.23 & 1.59 & 1.63 & - \\
\hline Oba-Qs & 12 & 0.34 & 0.054 & 2.09 & 0.45 & -232 \\
\hline CFP' & 16 & 0.69 & 0.69 & 3.78 & 3.62 & - \\
\hline Oba-Qc & 18 & 0.41 & 0.18 & 3.62 & 1.55 & -249 \\
\hline
\end{tabular}



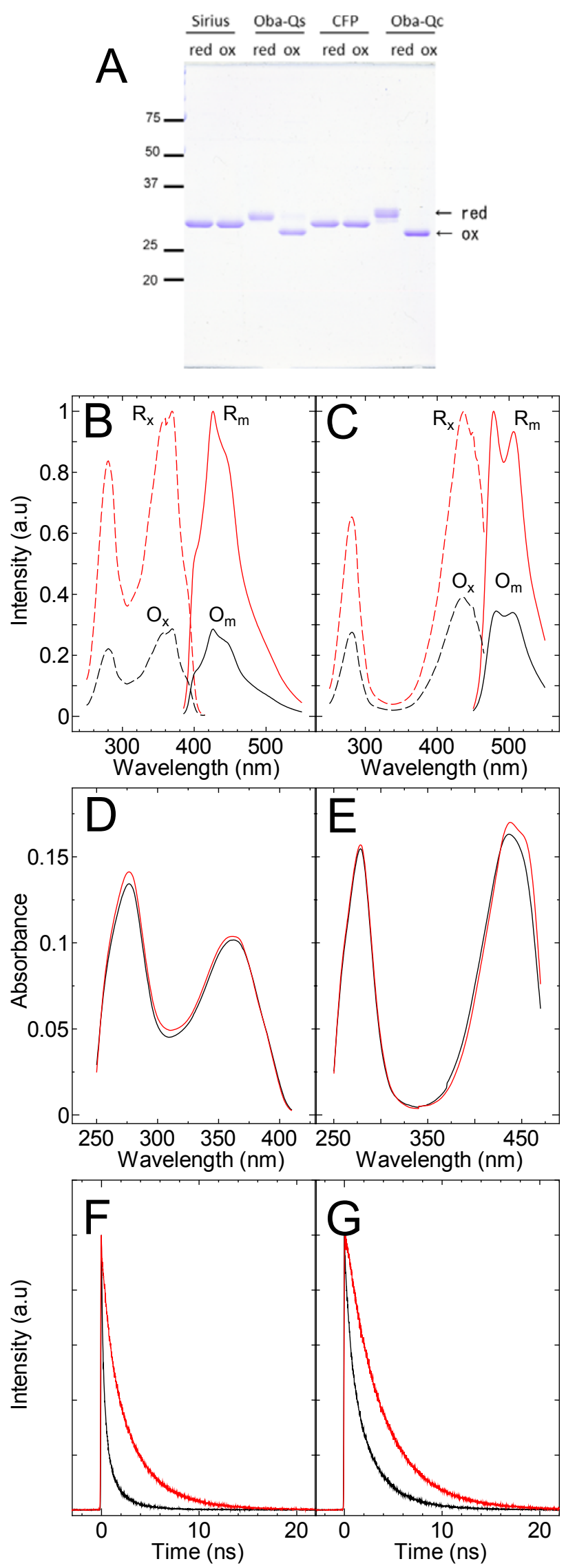

Fig.1 

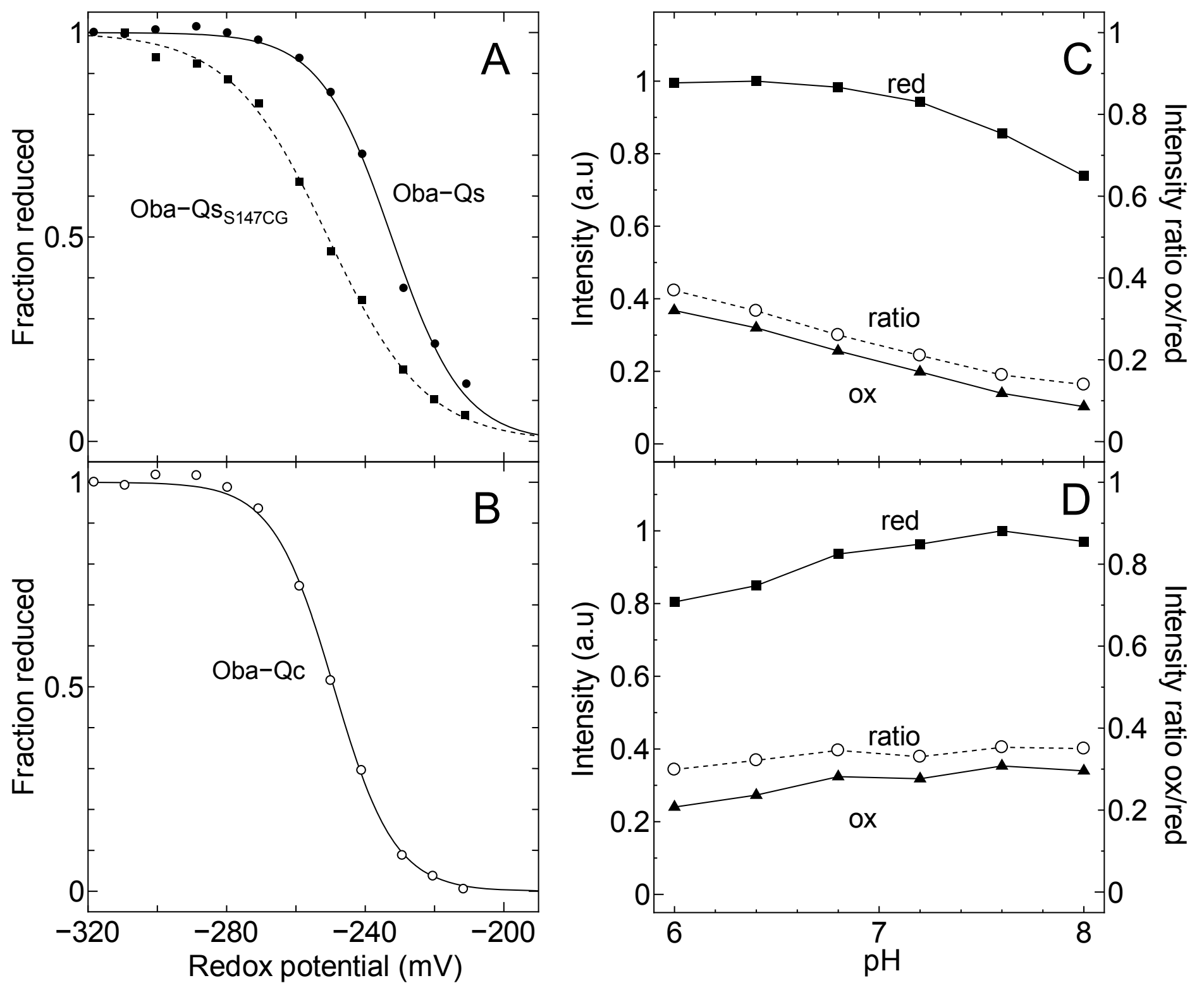

Fig.2 

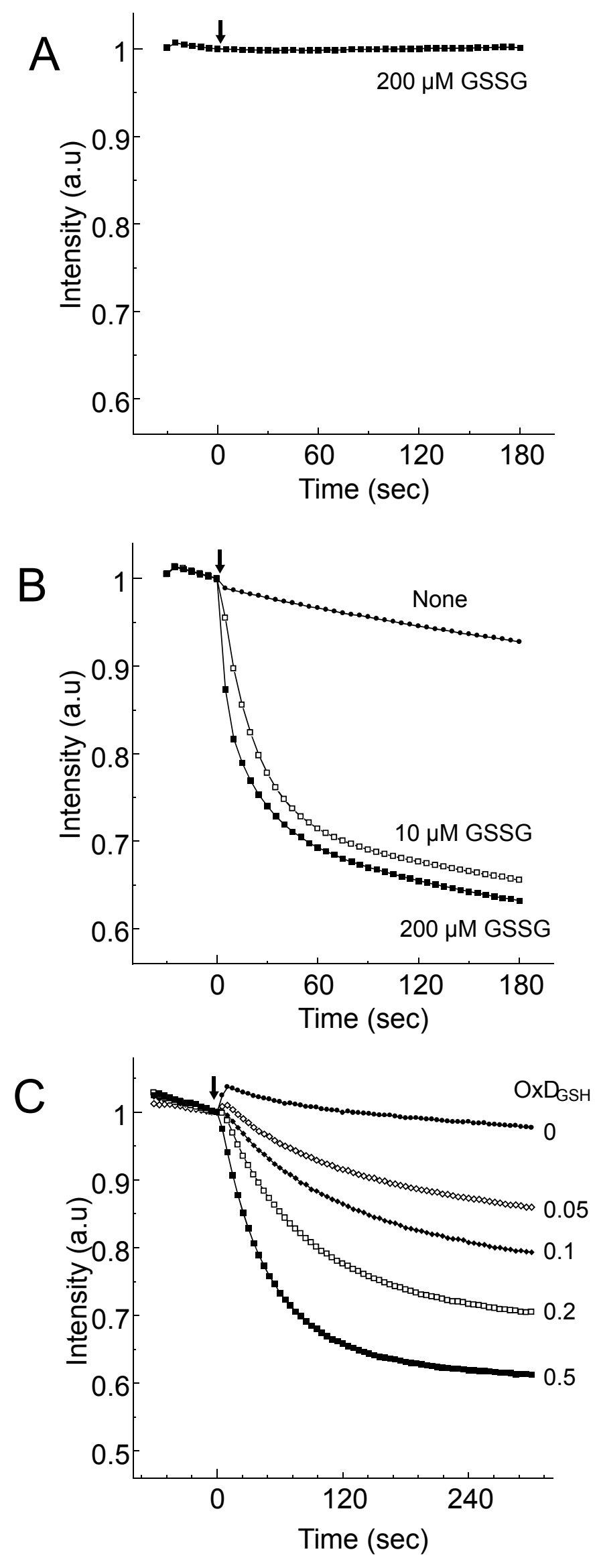

Fig 3 

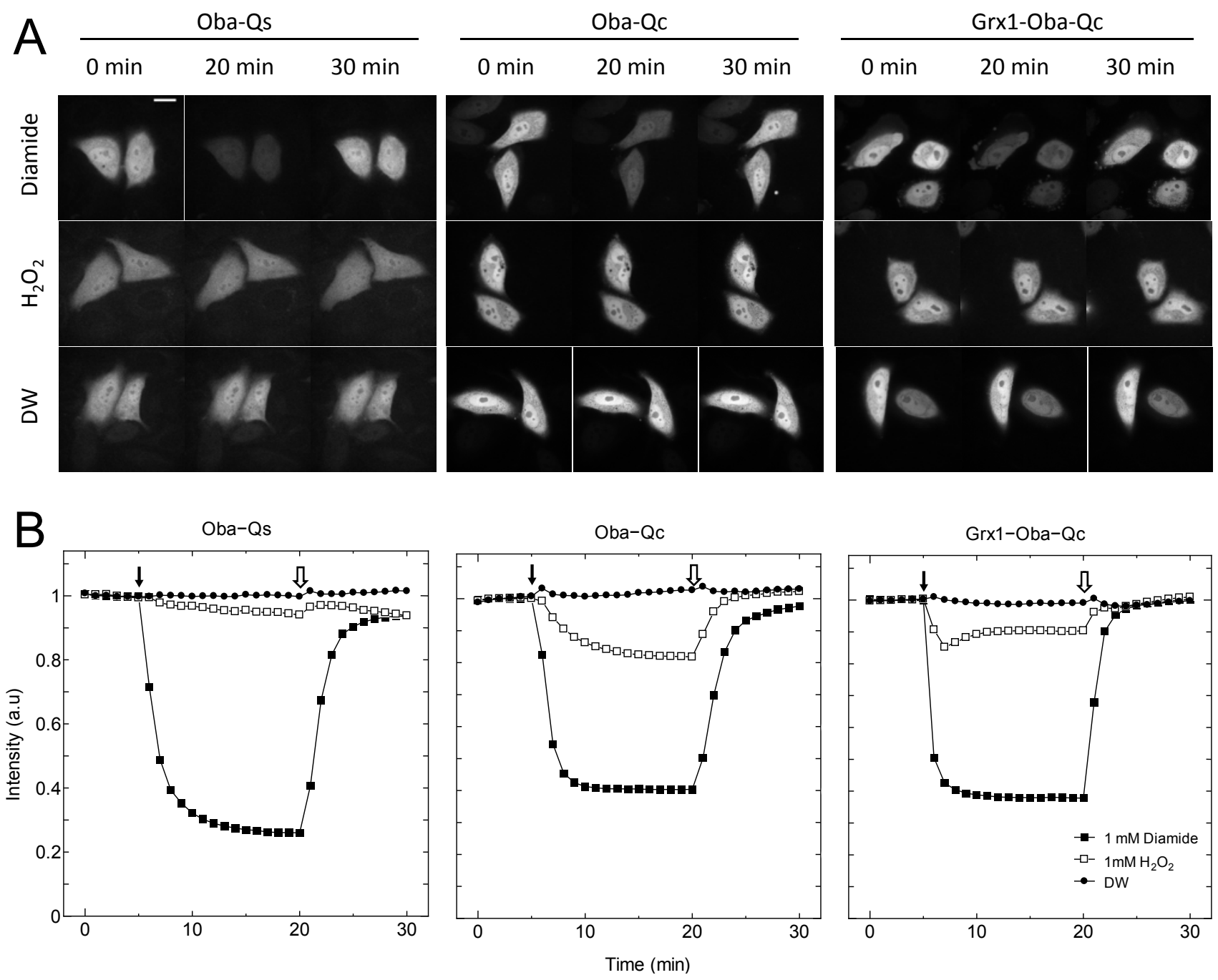

Fig. 4 